\title{
De cuando Pinocho aprende valores. Una lectura de la novela de Collodi a la luz de las teorías de Shalom H. Schwartz y Leonardo Boff
}

\author{
Carlos Rubio Torres ${ }^{1}$ \\ Profesor en la Escuela de Formación Docente de la \\ Universidad de Costa Rica y la \\ División de Educación Básica, CIDE de la Universidad Nacional \\ Costa Rica
}

Recibido 21 de agosto de 2008 - Aprobado 23 de marzo de 2009

Resumen. Carlo Collodi publicó los capítulos de la novela Pinocho entre 1880 y 1883. Desde entonces, se ha convertido en una obra fundamental de la literatura universal. En este artículo se contempla la posibilidad de que Pinocho ayude al lector a construir valores, con base en las perspectivas del psicólogo social Shalom H. Schwartaz y el teólogo Leonardo Boff.

Palabras clave. Literatura infantil, valores, cinematografía infantil, consumismo.

Abstract. Carlo Collodi published the chapters of the story Pinocchio in a children's newspaper between 1880 and 1883. Since that time, Pinocchio has become universally known as a fundamental work in literature. Based on the perspectives of social psychologist Shalom H. Schwartaz and theologian Leonardo Boff, the author of this article contemplates the possibility that Pinocchio's story allows the reader to develop greater social and moral values for living.

Key words. Children's literature, values, children's cinematography, consumerism.

\footnotetext{
Profesor de literatura infantil en la Escuela de Formación Docente de la Universidad de Costa Rica y la División de Educación Básica del CIDE, en la Universidad Nacional. Doctorando en Educación por la Universidad de Costa Rica. Autor de Queremos jugar (cuentos, 1988), Pedro y su teatrino maravilloso (cuentos, 1993), Escuela de hechicería, matrícula abierta (novela, 1996), El libro de la Navidad (cuentos, 2001), La mujer que se sabía todos los cuentos (cuentos, 2003) y Papá es un campeón (novela, 2006).

Correo electrónico: autorcarlosrubio@yahoo.com
} 
Hace más de diez años interpreté, en una versión para la radio, el papel del muñeco de madera. Era la obra teatral El corazón de Pinocho, de don Carlos Luis Sáenz. Desde entonces, la marioneta no deja de guiñarme un ojo y de enseñarme raras coincidencias entre su vida y la mía.

Pues este cuento no es el de un rey, una reina o una princesa encerrada en un castillo. No, ésta es la historia de un pedazo de madera. Algún día, Maese Cereza quiso hacer, con él, la pata de una mesita. Pero, ¡cosa más rara! El trozo de palo le habló y exigió que no lo golpeara tan fuerte y, además, tuvo la osadía de pedir que no le hiciera cosquillas con el cepillo. Así, empezó una novela publicada por el italiano Carlo Collodi, hace menos de 130 años. Sin embargo, la figura de Pinocho nos parece tan antigua como las de los personajes de los ancestrales cuentos de hadas.

¿Se trata, acaso, de un libro pedagógico? ¿Permite aleccionar sobre los valores? Pascual (2003), Soriano (1995) y Hazard (1989) coinciden en que es una obra maestra de la literatura universal, y, sobre todo, porque está escrita para que las jóvenes generaciones disfruten de la lectura y se entretengan en sus momentos de ocio. No es un libro diseñado para explícitos procesos de enseñanza y de aprendizaje, ya que, a pesar de las continuas referencias al deber ser y a la orientación para que los lectores se conviertan en niños buenos, Pinocho nos invita a disfrutar con su sentido del humor, a horrorizarnos con los peligros a los que se expone, a enternecernos con su subrayada ingenuidad. Debe de ser, por eso, que el muñeco de madera no es sólo una de las máximas expresiones de la literatura italiana, sino que es un símbolo reconocido mundialmente.

Afortunadamente, el Consejo Superior de Educación (2008) incluyó Las aventuras de Pinocho en la lista de textos de lectura recomendada para el Primer Ciclo de la Educación General Básica. ¿Por qué no para el Segundo Ciclo? Dado que el libro se lee en las instituciones costarricenses de Educación primaria, es conveniente preguntarse sobre los posibles efectos que podría tener en las niñas y los niños. Ya Bettelheim (1990) advertía, en su clásico estudio, que en las lecturas de la infancia se experimenta una "lucha por el significado" y que los cuentos maravillosos pueden convertirse en fuentes de aprendizajes que se fijan, permanentemente, en el inconsciente. En el "placer de la lectura" se "vislumbra la vida desde el interior", y por eso, las imágenes de los cuentos de las niñas y los niños nos acompañan, aún en nuestra vida adulta.

Desde la perspectiva psicológica, Cashdan (2000) sostiene que en Pinocho se presenta la contraposición entre la holgazanería y la laboriosidad. El asunto central de la novela no es la mentira. Es común que el público rememore la película que Disney (1940) elaboró con base en la novela de Collodi, en la cual se representa la escena en la que el muñeco, encerrado en una jaula, miente y le crece la nariz. Si bien, ese crecimiento nasal, también, aparece en la obra literaria, no es la que da razón de ser al texto.

Posiblemente, el productor norteamericano cambió el tema central de la obra literaria, pues tal como lo apunta Cashdan (2000), en 1940, ya se habían aprobado, en los Estados Unidos, leyes sobre el trabajo infantil. No había necesidad de insistir en que los niños trabajaran -pues ya era una práctica ilegal-, por eso consideró conveniente hacer referencia a acciones reprobables en la niñez, como la de decir mentiras, fumar o tomar licor. Pero, en el texto original, en sus treinta y seis capítulos, se reitera la presencia de la dicotomía pereza/trabajo. Y debe tomarse en cuenta que el trabajo de las niñas y los niños, en ese momento, consistía en estudiar.

El texto fue escrito en un momento histórico, en el que se popularizaban las escuelas. Ya se percibía, en el mundo, los efectos de las ideas revolucionarias del pedagogo suizo Johann Heinrich Pestalozzi, quien había fundado en 1775 su primera escuela para niños pobres, y había influido 
a sus discípulos, entre ellos el alemán Johann Friedrich Herbart, considerado el fundador de la pedagogía científica y Friedrich Froebel, creador del concepto de las escuelas de párvulos, llamadas kindergarten o jardín de niños. Es más, tal como lo afirma Pascual (2003), en 1877, se promulgó la ley de enseñanza obligatoria en Italia. En pocas palabras: ya para la década del ochenta del siglo XIX, la educación de las personas jóvenes era importante. Y es notorio en Pinocho que el trabajo de los niños consiste en estudiar.

Por eso, en este ensayo se plantea, a manera de hipótesis, que más parece un nuevo pacto de lectura: la educación es un valor, y es posible estudiarla a la luz de los constructos teóricos de Schwartz (2001). Pero, Pinocho no sólo es una marioneta que experimenta continuos obstáculos que le impiden estudiar y convertirse en un niño verdadero. Es un personaje que vive intensamente la pobreza. Por eso, se harán reflexiones sobre lo que es educar en condiciones miserables, con base en la propuesta de Boff (2005 y 2007), con la finalidad de encontrar nuevas posibilidades de aprovechamiento de este clásico universal en las escuelas costarricenses.

\section{BREVE BIOGRAFÍA DE UN MUÑECO DE MADERA}

Tallado bruscamente, casi sin orejas -razón por la que, tal vez, no escucha los consejos de su padre, del Hada Azul o del Grillo Parlante-, ataviado con un traje de papel floreado y con un gorrito de miga de pan, Pinocho intenta, infructuosamente, instruirse en la escuela y complacer al buen Geppetto. ¿A quién se le ocurrió que una marioneta pudiera hablar y hacer travesuras? Pues, fue al toscano Carlo Lorenzini -conocido, mundialmente, como Carlo Collodi-, de quien no se sabe mucho. Fue un periodista político y solía publicar sus apreciaciones sobre la dividida Italia de finales del S. XIX. No se pasó la vida tras un escritorio, pues también combatió en dos guerras de independencia, en las que se desempeñó como cronista. El teatro, tampoco, le fue ajeno, ya que fue crítico, director escénico y censor teatral. De él, apenas, queda un retrato y una que otra caricatura publicada en diarios de la época.

Resulta extraño que un periodista y soldado se convierta en uno de los escritores más renombrados de literatura infantil. Y es que tampoco fue un asiduo creador de arte para niños. En 1875, tradujo los cuentos del francés Perrault (conocido, mundialmente, por su colección de relatos, publicada por primera vez en 1697 , en la que aparecen textos fundamentales de la niñez, tales como Caperucita roja, La Cenicienta o El zapatito de cristal, Barba azul o La bella durmiente del bosque), las obras de Madame d’Aulnoy y Madame Leprince de Beaumont (institutriz de quien se rescata la conocida versión de La Bella y la Bestia).

La traducción de clásicos habrá resultado fundamental en su formación como escritor, pues, como lo afirma Soriano (1995), se le encargó escribir una nueva versión del Giannetto de Parravicini, una obra didáctica publicada, por primera vez, en 1837. Casi cuarenta años después, Collodi la convierte en una obra humorística, de gran éxito entre los niños, a la que tituló Giannettino.

Es posible que Pinocho no existiera si a Ferdinando Martini no se le hubiera ocurrido fundar, en 1880, un periódico para niños, titulado, precisamente, Gionarle per i Bambini. Carlo Collodi quiso colaborar con la iniciativa y le envió unas cuartillas al editor. Era, ni más ni menos, que el primer capítulo de un relato que, en ese momento se llamaba Historia de un muñeco, acompañado de una carta en la que expresaba: "Ahí te mando esa chiquillada; haz con ella lo que te parezca; pero, si la publicas, págamela bien, para que me entren las ganas de proseguirla”. Así fue como el 7 de julio de 1881 aparece el inicio del conocido texto, en la tercera página del primer número del Gionarle. 
No hubo que esperar para percibir el éxito de la historia de Collodi. Eran muchas las cartas que los lectores enviaban pidiendo más aventuras de Pinocho. Los editores tuvieron que batallar con la reconocida pereza de su autor, quien, a su antojo, dejaba pasar semanas sin dar señales de vida. Pascual (2003) y Soriano (1995) hacen ver que la desordenada estructura de Pinocho es una expresión de la dejadez y la indiferencia con que el autor se tomaba la continuación de la novela, sin importarle el enojo de Martini y los pequeños lectores.

No es de extrañar que los editores recortaran los capítulos que escribía el periodista, para dar tiempo a que llegaran otros que pudieran publicar. Hastiado por tanta insistencia, Collodi decidió que Pinocho muriera ahorcado en el actual capítulo XV. Los lectores protestaron, con misivas y amenazas de no leer más el Giornale, por lo que tuvo que continuar su odiosa tarea hasta llegar al capítulo XXXVI, en la que el muñeco de madera, por fin, se convierte en un niño verdadero.

Raro nombre el que escogiera para el muñeco: Pinocho. En la versión cinematográfica de Disney (1940), Pepito Grillo denomina con el hipocorístico Pino a la marioneta, y da la impresión de que, efectivamente, estuviera hecha de madera sacada de un pino. Sin embargo, en el capítulo II, encontramos otra pista: Geppetto entró al taller de Maese Cereza, quien, en el suelo, se encontraba angustiado porque al garrote, con que intentaba hacer la pata de una mesa, le dio por hablar. Geppeto buscaba un trozo de madera para crear una marioneta y recorrer el mundo con ella.

En ese momento, el pedazo de palo gritó: “ßBravo, Panocha!”, haciendo alusión a que la peluca amarilla del titiritero parecía una panocha, que en italiano, significa "mazorca". Creyéndose ofendido por Maese Cereza, por comparar su peluca con el pelo del maíz, Geppetto lo reta a pelear, y después de darse golpes por el piso, termina convenciéndose que quien lo llama "Panocha" es el trozo de madera. Se lo lleva a su casa e inicia la talla de la figura: "¿Qué nombre le pondré? -se preguntó-. Voy a llamarlo Pinocho. Sí, ese nombre le dará suerte. Conocí a toda una familia de Pinochos: Pinocho el padre, Pinocha la madre y Pinochos los hijos, y a todos les iba bien. El más rico pedía limosna" (Collodi, 2003, p. 16) ${ }^{2}$.

Collodi concluyó la historia en 1883, tras dos años de tensiones con los editores del periódico infantil. Ese mismo año, recoge las entregas en un libro que llamará Las aventuras de Pinocho, el que se convierte en una de las obras más traducidas, reescritas y adaptadas al teatro y al cine a escala mundial. El autor no pudo darse cuenta de ello, pues falleció en 1890, cuando aún no había cumplido los 64 años.

\section{AVENTURAS Y DESVENTURAS EN EL APRENDIZAJE DE LOS VALORES}

El muñeco se encierra en una habitación y se encuentra con un grillo parlante, tal como se relata en el capítulo IV. El insecto le informa que vive allí desde hace más de cien años y le advierte: "-¡Ay de los niños que se rebelan contra sus padres y abandonan por capricho la casa paterna! Nunca encontrarán paz en este mundo, y antes o después se arrepentirán amargamente” (Collodi, p. 23).

Pinocho le lanza un golpe con el mazo y lo aplasta brutalmente. El grillo parlante -quien, en la conocida versión cinematográfica de Disney (1940), se convierte en Pepito Grillo-, así como la

\footnotetext{
Para no repetir, con insistencia, la fecha, se aclara que se hace uso del texto completo de Las aventuras de Pinocho, traducido al español por Teresa Clavel (2003). En este libro aparece la magnífica compilación de ilustraciones antiguas, realizada por Cooper Edens. Sin embargo, se mantiene como referencia la traducción de Chema Heras (2005), acompañada de las memorables ilustraciones de Roberto Innocenti. No se puede perder de vista que la Editorial Costa Rica publicó, con motivo del centenario de la obra, una edición de Pinocho, con hermosas ilustraciones de Juan Manuel Sánchez (1983).jUn homenaje para el artista, quien precisamente empezó su carrera con los dibujos de Cuentos de mi tía Panchita, de Carmen Lyra!
} 
figura del Hada Azul y la figura paterna de Geppetto se hacen portavoces de los valores, los cuales deben ser vividos en las muy distintas circunstancias que viva el muñeco. Tal como lo señalan Molpeceres, Llinares y Musitu (2001), los valores educativos fundamentales son transmitidos por los padres, quienes evalúan y confrontan la adecuación y el potencial adaptativo de sus valores a la vida de sus hijos. ¡Resulta difícil que Pinocho haga suyos los valores de sus padres! Geppetto, el Hada y el grillo son ecos continuos de la conciencia y pueden ser representados en la definición que Schwartz (2001) hace de los valores, como "metas deseables y transituacionales, que varían en importancia y sirven como principios en la vida de una persona o de otra entidad social"

En esa definición se considera que los valores sirven a los intereses de una entidad social, y, de esa manera, encontramos que Pinocho, cuando convive con el Hada Azul en la Isla de las Abejas Industriosas (capítulo XXIV), parece descubrir, por fin, el valor del trabajo, y puede permanecer un período sin peripecias, en sana convivencia con la sociedad. La marioneta encuentra tranquilidad cuando sirve a los demás, en pro de un beneficio comunitario. Asimismo, Schwartz (2001) afirma que los valores motivan la acción, dándole dirección e intensidad. Esa motivación es la que vive la marioneta, mientras se dirige, por primera vez, a la escuela. Expresa, en el capítulo IX:

-Hoy, en el colegio, aprenderé a leer enseguida; mañana aprenderé a escribir, y pasado mañana aprenderé a contar. Luego, con mi habilidad, ganaré mucho dinero, y con el primer dinero que consiga, le haré a mi papá una bonita chaqueta de paño. Pero, ¿qué digo de paño? Quiero hacérsela de plata y de oro, y con los botones de brillantes (Collodi, p. 37).

El hecho de educarse motiva a Pinocho y le da sentido a su vida. Sin embargo, no había caminado unos pasos, cuando decide no asistir a clases para disfrutar la función del Gran Teatro de Marionetas. Y allí, se mete en intrincados problemas.

Schwartz (2001) afirma que los valores funcionan como criterios para juzgar y justificar la acción. Por eso, no es de extrañar que el muñeco, quien ha sido obligado a actuar como un perro guardián, encadenado con un ancho collar erizado de púas metálicas, cumpla con la labor de alertar a su amo, un campesino, el momento en que aparecen las garduñas a robar gallinas. En el capítulo XXII, una garduña le ofrece a Pinocho hacer un pacto que consiste en que le permita robar ocho gallinas (siete se las comen las ladronas y la octava es entregada, a manera de premio, a Pinocho). El muñeco no acepta participar del acto de corrupción y ladra para despertar al campesino y expresa:

[...] las garduñas me han despertado con su parloteo y una ha venido a la caseta a decirme: "Si prometes no ladrar y no despertar al amo, te regalaremos una gallina desplumada”. ¡Habrase visto! ¡Tener la desfachatez de hacerme a mí semejante proposición! ¡Porque yo soy una marioneta y tendré todos los defectos del mundo, pero nunca me conchabaré con malhechores ni seré cómplice de sus fechorías! (Collodi, p. 89)

Como premio, a Pinocho le quitan el collar de perro.

Schwartz (2001) señala que los valores se adquieren por medio de la socialización en los valores del grupo dominante, y de la experiencia personal de aprendizaje. A lo largo de la novela, el grillo parlante, el Hada Azul y Geppetto tratan de aleccionar a Pinocho acerca de los valores del grupo dominante, y por medio de múltiples experiencias (algunas muy dolorosas, como la de ser ahorcado y resucitado de milagro, la de ser convertido en un burro y humillado, a punta de 
latigazos en el escenario de un teatro o ser devorado por un inmenso tiburón), el muñeco aprende los conocimientos necesarios para transformarse en un niño de verdad.

Entre las muchas bondades que puede tener este texto literario, está la de sugerirnos que sólo con la práctica de valores podemos alcanzar el sentido de humanidad. Por eso, Geppetto le dice a su hijo, ya redimido como un muchacho de carne y hueso: "Porque cuando los niños malos se vuelven buenos, tienen la virtud de hacer que todo adquiera un aspecto nuevo y sonriente, incluso en su familia" (Collodi, p. 170).

Se puede afirmar, junto con Schwartz (2001), que Pinocho tiene como meta central alcanzar el logro, el éxito personal mediante la educación y las atenciones a su progenitor. "Estudiaré, trabajaré, haré todo lo que me digas" (Collodi, p.104), asegura Pinocho al Hada Azul, cuando, por fin, decide ir a la escuela. Tal como lo propone Schwartz, en los ejemplos de valores que propone en la tabla titulada "Tipos motivacionales de valores", para alcanzar el logro es necesario que la persona sea exitosa, capaz y ambiciosa. Sin embargo, continuamente, la marioneta pierde la capacidad de alcanzar el cometido y abandona la posibilidad de estudiar. De hecho, en el capítulo XXIX, se afirma que, afortunadamente, el personaje decide tomar en serio el estudio. Se describe de esta manera: “[...] en los exámenes finales tuvo el honor de ser el mejor del colegio; y su comportamiento, en general, fue considerado tan loable y satisfactorio que el Hada, muy contenta, le dijo: -¡Mañana se hará por fin tu deseo! - ¿Cuál? -Mañana dejarás de ser una marioneta de madera y te convertirás en un niño de carne y hueso" (Collodi, pp. 122-123).

Sin embargo, Pinocho decide acompañar a su amigo, Romeo, a quien apodan Palillo, al País de los Juegos, donde no hay colegios, maestros o libros. Es un país donde no se estudia nunca. Los jueves no hay clase, y las semanas están compuestas por seis jueves y un domingo. Las vacaciones de enero empiezan el $1^{\circ}$ de enero y terminan el 31 de diciembre. Palillo no duda en afirmar: "¡Así deberían ser todos los países civilizados!" (Collodi, p. 125).

Es un verdadero festival el País de los Juegos. Se puede jugar canicas, pelota, montar velocípedo o caballitos de madera. En las paredes están mal escritas frases como "Viva los jugetes", "No keremos mas colejios” o “¡Abajo Lari Metica!”. (Nótese el desprecio por la intervención educativa en la vida de las personas). Lo que menos se imaginan Pinocho y Palillo, es que los niños que habitan ese país se convierten en burros. El muñeco se lamenta de su horroroso aspecto y de que, en vez de hablar, sólo pueda rebuznar. Una marmota le dice: “[...] todos los niños haraganes que no quieren saber nada de libros, el colegio y los maestros, y se pasan el día jugando y divirtiéndose, antes o después, acaban convirtiéndose en borricos" (Collodi, p. 136).

Se resalta el sentido manifiesto que tiene la instrucción para el muñeco de madera. Es mediante el logro, tal como afirma Schwartz (2001), la demostración de las competencias según los criterios sociales, que la marioneta puede alcanzar el fin de convertirse en un ser de carne y hueso. Al desviarse del camino trazado por sí mismo y por la sociedad, termina transformado en un triste y maltratado pollino.

Precisamente, la incapacidad manifiesta del muñeco de alcanzar las metas que se propone (y de ejecutar los valores enseñados por sus mayores), hace referencia a otra meta señalada por Schwartz (2001): la de la autodirección. Será porque se trata de un muñeco que, por su naturaleza, estaría acostumbrado a no moverse por sí mismo, y a esperar que un titiritero lo haga actuar a su antojo, tirando de los hilos. ¿Será por eso que Pinocho no tiene pensamiento independiente? ¿Será por eso que lo convencen, tan fácilmente, de que abandone los estudios?

Tragafuegos es un hombre grotesco, de larga barba y mal genio, dueño de una compañía de marionetas. En el capítulo X, se describe cómo este personaje amenaza a Pinocho con utilizarlo como un leño que avive el fuego. El muñeco chilla, desesperadamente, pidiendo misericordia. El 
gigantón lo perdona y le regala cinco monedas de oro, con la encomienda de que debe entregárselas a su padre, Geppetto.

Feliz, con aquel tesoro entre las manos, Pinocho corre de regreso a su casa. Sin embargo, se encuentra con el Zorro y el Gato, quienes lo embaucan, invitándolo a sembrar las monedas en el País de los Gaznápiros. De esa manera, tendrá la posibilidad de hacer brotar un árbol cuyos frutos serán innumerables monedas de oro: "Tus cinco cequíes se convertirán de un día para otro en dos mil" (Collodi, p. 48), afirma el Zorro con certeza. Con base en las aseveraciones de Schwartz (2001), se puede decir que la marioneta carece de pensamiento independiente y no elige, de forma creativa, las acciones que desea ser. Al fin y al cabo, su naturaleza es la de un muñeco de madera, diseñado para que sus acciones se desarrollen según los deseos de un artista que tira de los hilos.

Una de las magistrales ilustraciones que Roberto Innocenti hace en su Pinocho es la que representa el encuentro de la marioneta con el Zorro y el Gato, (Collodi, pp. 50-51) ${ }^{3}$, en la que logra una vista aérea. Un paisaje desolado, frío, cubierto por nieve y árboles sin hojas, casas pobres y gente aterida. Se puede observar al Zorro (quien simula ser cojo), y al Gato (quien simula ser tuerto) saludar, amigablemente, al muñeco. A la derecha de la ilustración, se contempla a Pinocho mostrando las cinco monedas de oro. El Gato ha abierto los dos ojos y el Zorro ya no se apoya en la muleta. ¡Qué mejor manera de aprender acerca de la elección de las acciones y las consecuencias de no actuar con un ejercicio responsable de la libertad! Ya Molpeceres, Llinares y Musitu (2001) citan la investigación de Mueller y Wornhoff, en la que se analiza la prescripción personal y social de algunos valores, entre ellos, el de la belleza, y se llegó a la conclusión de que las personas consideran que la belleza es importante para sus vidas -no necesariamente, importante para las de los demás-. Se aprenden los valores, de manera sutil, de la mano de la lectura de Pinocho y de Innocenti, un maestro de la estética contemporánea.

Como es de esperar, el Zorro y el Gato comen desmedidamente, a costilla de Pinocho en la Posada del Cangrejo Rojo. Después de que la marioneta siembra las monedas restantes en el falso País de los Gaznápiros, los dos animales huyen con el tesoro. El muñeco, engañado y traicionado, vuelve a quedar en la pobreza. Incluso, Collodi (en el capítulo XIV), narra cómo Pinocho es perseguido por unos asesinos, que no son otros que el Zorro y el Gato disfrazados, cubiertos con sábanas.

Bien parece que Pinocho es un hedonista. Busca el placer y la gratificación sensual consigo mismo. Por eso, expresa sin reparo: "Y yo, para ser sincero, no tengo ninguna gana de estudiar; me divierto más corriendo tras las mariposas y trepando a los árboles para coger pajaritos de los nidos", (Collodi, p. 23). O bien, el narrador describe que la marioneta, en el País de los Juguetes, "llevaba (junto a su amigo, Palillo) ya cinco meses dándose la gran vida, jugando y divirtiéndose todo el día, sin ver por asomo un libro o un colegio [...]" (Collodi, p. 133). Con base en los criterios de Schwartz (2001), se puede decir que Pinocho quiere vivir intensamente los valores del placer y del disfrutar de la vida.

No en vano, la marioneta insiste, en varias ocasiones, en la necesidad de satisfacer su organismo, principalmente, la de aplacar el hambre, razón por la cual, en el capítulo V, intenta hacer una tortilla con un huevo, pero al quebrarlo, desprende un pollito, que sale volando por la ventana. O bien, en el capítulo XXIX, el muñeco está a punto de morir de hambre. Un caracol, con órdenes

Me refiero a la edición de la Editorial Kalandraka (2005), en la cual aparecen las ilustraciones que Innocenti realizó en 1988. Olbius Suari (2003) hace un análisis de este trabajo gráfico, titulado Pinocho de Innocenti: el encanto de la pulcritud. La autora afirma que las ilustraciones de Innocenti "supusieron un antes y un después en la historia de la ilustración del clásico" y se convirtieron en un "fresco de la época y el lugar donde se desarrolla la novela". 
del hada, tarda tres horas y media en aparecer con una bandeja de plata en la cabeza. Encima de eso, lo que trae consigo es un pan de yeso, un pollo de cartón y cuatro albaricoques de alabastro. Y todo esto ocurre porque Pinocho es egoísta y sólo piensa en su autosatisfacción.

Tal vez, Collodi, inconscientemente, nos propone la tensión entre los valores que se encuentran entre la autopromoción y la autotrascendencia. El muñeco desea alcanzar el logro y el hedonismo (centrados en la satisfacción personal), pero se encuentra en conflicto con los valores de la tradición y la benevolencia. Por esto, el huevo se le transforma en pájaro y el caracol tarda insoportables horas en aparecer, con comida imposible de digerir. La marioneta no ha logrado una conciliación o un equilibrio entre la satisfacción de sus necesidades y la de los demás.

En una lucha continua con su naturaleza (¿será la de ser de madera, la que crece sin pensamiento?), que a Pinocho le cuesta tanto aceptar la meta central de la conformidad. No obedece a su padre, no escucha al Grillo Parlante y olvida, fácilmente, las recomendaciones del Hada Azul. No restringe sus acciones, por eso, en el capítulo XVIII vuelve a confiar en el Zorro y el Gato -quienes, ya, evidentemente, lo habían engañado-, y conviene con ellos en sembrar de nuevo sus monedas en el Campo de los Milagros, (siempre en espera del nacimiento del imposible árbol cuyos frutos son monedas). Por eso, se pelea con sus compañeros de escuela, lo cual lo mete en serios problemas, pues los policías lo arrestan con la creencia de que ha herido a otro niño.

Por tal motivo, no puede alcanzar su más preciado deseo: verse a sí mismo como un ser humano. Sólo cuando la marioneta, apoyada en las bases de los conocimientos que construye por medio de la interacción social, fundamentado en los valores de los que se apropia en contacto con el grupo de personas que lo rodean (básicamente, Geppeto, el grillo parlante y el Hada), logra hacerse de buenos modales, de la obediencia y de la honra a sus padres y sus mayores; sólo cuando ha logrado establecer un equilibrio entre los valores que se encuentran en tensión entre la autopromoción y la autotrascendencia, sólo en ese momento, se siente preparado para convertirse en un auténtico ser humano.

Debe de ser por eso, que mientras el muñeco duerme, se le aparece el Hada Azul y le expresa:

-¡Muy bien, Pinocho! Por tu buen corazón, te perdono todas las travesuras que has hecho hasta hoy. Todos los niños que ayudan cariñosamente a sus padres en la miseria y en la enfermedad merecen alabanzas y afecto, aunque no puedan ser citados como modelos de obediencia y de buena conducta. Sé juicioso en el futuro y serás feliz. (Collodi, pp. 169-170).

Nos encontramos en el capítulo XXXVI y el señor Collodi se resiste a escribir más, aunque los editores del Gionarle per i Bambini le ofrezcan duplicarle el pago. Molpeceres, Llinares y Musitu (2001), con base en la teoría de Durkheim, dirían que el protagonista ha aprendido un sentido de disciplina, un sentimiento de solidaridad y de vinculación con los grupos sociales, y un sentido de identidad. Cuando Pinocho alcanza la meta de la conformidad, cuando logra el equilibrio de las tensiones, desde la perspectiva de Schwartz (2001), se convierte en un niño verdadero y le coloca al texto el punto final.

\section{POBRE DE OFICIO, MUÑECO DE MUCHO BENEFICIO}

Lleno de algarabía, Pinocho baila con los títeres del Teatro de Muñecos. Bastantes razones tiene para danzar, pues por poco muere quemado en una hoguera. Tragafuegos, el dueño de la 
compañía artística decide, de vez en cuando, lanzar un actor de madera al fuego. Afortunadamente, ha desistido de proseguir con ese acto y llama al protagonista y le pregunta: "-¿Cómo se llama tu padre? -Geppetto. -¿Y cuál es su oficio? -El de pobre.-¿Gana mucho? -Gana lo necesario como para no tener nunca un céntimo en el bolsillo" (Collodi, p. 45).

La continua insistencia en la pobreza de Pinocho puede ser un reflejo de las penurias económicas vividas por el propio Collodi, quien encontró, en la creación de la novela, una manera de hacer dinero. Recordemos el pedido expreso hecho al editor: "Si publicas (la historia), págamela bien, para que me entren las ganas de proseguirla". Al fin y al cabo, como lo afirma Lionni (1985), "un buen libro para niños es, inevitablemente, una autobiografía" y existen razones para pensar que esa pobreza sentida por el muñeco y su padre Geppetto, no sólo es una expresión de un hombre que vivió hace más de un siglo en Toscana. Es la pobreza de la humanidad.

El padre y el hijo convienen en que en la educación existe una forma de abandonar la miseria. Tal conveniencia es un presupuesto de lectura, ya que se asume que la instrucción es un medio que permite humanizar a Pinocho. Tal como lo afirma Sachs (2006), haciendo referencia al filósofo, político y matemático, Marqués de Condorcet (1743-1794), quien, dos años antes de envenenarse (resistiéndose a morir en el cadalso, por voluntad de los jacobinos), presentó el Rapport et project de décret sur l' organisation générale de l'instruction publique, el cual se convirtió en norma en la pedagogía republicana. En los escritos de este hombre de la Ilustración, se evidencia que ya en tiempos de la Revolución Francesa, se percibía que la educación permitía a los individuos valerse por sí mismos, evitar a los charlatanes, abandonar supersticiones inútiles y nocivas, mejorar su ética y su "bondad moral".

Guiado por el principio propuesto por Condorcet, citado por Sachs (2006), de que "a mayor educación, incluida la educación de los principios sociales y políticos, más pacífica, sensata y progresista sería la sociedad en su conjunto", Geppetto no duda en hacerle un traje de papel floreado, un par de zapatos de corteza de árbol y un gorrito de miga de pan. Y, haciendo un esfuerzo mayor, vende su única y remendada chaqueta de pana en pleno invierno, pues necesita dinero para comprar un abecedario para su hijo. ¡Es imposible que un niño asista a la escuela sin abecedario!

Pero, Pinocho no tiene capacidad de valorar que la ilustración puede darle razones para progresar individual y socialmente. Ni siquiera sabe leer un cartel. En el capítulo IX, Collodi narra el camino del muñeco hacia la escuela. Y allí se encuentra con el Gran Teatro de Marionetas. La entrada cuesta cuatro sueldos, y el protagonista no tiene ni una sola moneda encima. En un impulso de deseo por entrar al teatro, vende su abecedario a un trapero por la suma exacta de los cuatro sueldos. "Y el libro fue vendido allí mismo al instante. ¡Y pensar que el pobre Geppetto se había quedado en la casa en mangas de camisa, temblando de frío, para comprarle un abecedario nuevo a su hijo!" (Collodi, p. 38).

Son muchas las desventuras que aguardan a Pinocho. Su llegada al Gran Teatro de Muñecos es celebrada con algarabía y desorden por las marionetas. Eso provoca la ira de Tragafuegos, el dueño de la compañía, quien lo condena a morir en una hoguera. De la misma manera, es válido hacer referencia al ya citado hecho de que el Zorro y el Gato lo convencen de que siembre sus cinco monedas de oro, con la finalidad de hacer brotar un árbol cuyos frutos son innumerables monedas de ese valor (capítulo XII). Son el mismo Zorro y el mismo Gato quienes, aparte de estafarlo, lo cuelgan de la gran encina (capítulo XV), lo cual advierte que la persecución desmedida de bienes materiales puede llevar a la destrucción.

En su lectura del salmo 23, titulada El Señor es mi Pastor, consuelo divino para el desamparo humano, Boff (2005) plantea que el sistema, en el cual vivimos, es consumista. Aumenta, constantemente, la oferta de objetos de deseo que pueden ser comprados y consumidos. Para ello, 
hace uso de la publicidad, cuya función consiste en excitar, constantemente, el deseo y el instinto de poseer bienes. De esa misma manera, Pinocho fue motivado a poseer una entrada para entrar al Gran Teatro de Muñecos y no dudó en deshacerse del abecedario (símbolo de la educación que desea legarle su padre). La marioneta desea ingresar al teatro, y siente que así, adquiere poder.

De forma semejante, los seres humanos compiten, en los términos de Boff (2005), por fumar determinada marca de cigarros, comprar un modelo de automóvil o utilizar ropa de diseñador. En este sistema, se hacen patentes las desigualdades entre los seres humanos. El 20\% de la humanidad acumula objetos de deseo, mientras que el $80 \%$ vive en la más absoluta carencia. Boff incluye, dentro de los objetos de deseo: la ciencia, el arte, cierto tipo de religión y de camino espiritual (todo ello está ofertado dentro de un mercado de consumo). Este mismo autor (2007), en su conferencia de apertura a los cursos de la Escuela de Estudios Generales de la Universidad de Costa Rica, expresa que el sistema económico absorbió lo político y que hace de todo una mercancía ${ }^{4}$.

La sobreabundancia de objetos de deseo, tal como los describe Boff (2005), no trae felicidad ni autorrealización. Tan sólo constituyen un espejo imaginario, una ilusión, que deja, a manera de legado, el estrés, el vacío y la desdicha. Por eso, llama la atención que Pinocho, a diferencia de los tradicionales cuentos de hadas, no concluye lleno de riqueza. El muñeco convive con su padre en una cabaña que le regaló el Hada Azul (no es un palacio, es una cabaña, pero es ideal para que padre e hijo puedan vivir en armonía). Para poder comprar una taza de leche fresca, la marioneta se ve obligada a trabajar dando cien vueltas a una noria, sacando cubos de agua fresca. En sus ratos libres, hace cestos y hasta logra construir una silla de ruedas para pasear a su viejo papá.

Y a pesar de ello, tiene un rato para continuar sus estudios y conocer más de letras y números. En otras palabras, Collodi -al igual que Boff- nos dice que es posible alcanzar la felicidad en la sencillez, y que no es conveniente caer en argucias ni corrupción para apropiarse de bienes materiales.

Después de agotadores días de trabajo, Pinocho decide comprarse un traje nuevo con cuarenta sueldos. En el camino, aparece el caracol, quien le dice que el Hada Azul yace, en la mayor miseria, en la cama de un hospital. El muñeco no duda en enviarle el dinero que tiene encima y de trabajar cinco horas extra por día para darle más. Esa misma noche, el hada le devuelve los cuarenta sueldos y lo convierte en un niño verdadero. Debe de ser que, cuando el ser humano logra deshacerse de lo propio por el bienestar de los demás, alcanza, al igual que el protagonista de esta historia, la condición de humanidad.

\section{¡QUÉ CÓMICO RESULTABA CUANDO ERA UNA MARIONETA!}

Así se expresa Pinocho, cuando mira el muñeco que ya ha dejado de ser. Y agrega: "¡Y qué contento estoy de haberme convertido en un niño de verdad!". Muchas lectoras y muchos lectores, independientemente de su edad, pueden sentir una satisfacción de identificarse con un personaje que se ha redimido y transformado en persona, después de vivir tantas peripecias. Tal vez, ese sea el motivo por el que la obra de Collodi continúe reeditándose, traduciéndose y transformándose.

Tal como ya se había expresado, el Consejo Superior de Educación (2008) aprobó la obra Las aventuras de Pinocho como lectura recomendada para el Primer Ciclo de la Educación General

\footnotetext{
Ahora, caigo en la cuenta de que el mismo texto de Pinocho es mercancía. No lo digo sólo por la apropiación que ha hecho Disney. No en vano, Lluch (2004), expresa que Disney tiene el copyright de la fantasía. Según me han contado viajeras recientes, en Toscana existen tiendas especializadas en libros y objetos que recuerdan a Pinocho. Si Collodi pudiera verlo... jexigiría mucho dinero! Eso permitiría referirse a la globalización y al arte como bien de consumo, por supuesto, en otro ensayo.
} 
Básica este año. Las niñas y los niños, de manera sutil y emocionante, podrán construir algunos de los principios sobre teoría de los valores mencionados por Schwartz (2001), como metas deseables y transituacionales, aplicables en diferentes momentos de sus vidas. En la tensión que existe entre la autopromoción y la autotrascendencia, el lector descubre un equilibrio entre el hedonismo y la tradición, entre sus logros y la benevolencia, o entre el poder y el universalismo.

De la misma forma, en medio de una sociedad de consumo, se observa que, por medio de la lectura de Pinocho, es posible descubrir los peligros de adquirir, desmedida e irresponsablemente, los objetos del deseo, y que es posible encontrar felicidad en la sencillez.

Es muy posible que la verdadera importancia de Pinocho radique en el hecho de que las lectoras y los lectores encuentran placer en divertirse con las descabelladas ocurrencias de la marioneta, así como en experimentar el pánico de ser destruido, o de no poder resistir la tentación de desviarse del camino a la escuela. Porque, al fin y al cabo, los seres humanos, al igual que el muñeco de madera, hemos enfrentado el reto de desprendernos de la comodidad de los hilos y de atrevernos a actuar, por cuenta y riesgo, en el prodigioso escenario de nuestra existencia.

\section{REFERENCIAS}

Bettelheim, B. (1990). Psicoanálisis de los cuentos de hadas. (10ª ed.). Barcelona, España: Crítica.

Boff, L. (2005). El Señor es mi Pastor. Consuelo divino para el desamparo humano. Cantabria, España: SalTerrae.

Boff, L. (2007). Humanidades hoy en América Latina. Conferencia de inauguración de los cursos de la Escuela de Estudios Generales de la Universidad de Costa Rica. San José, Costa Rica.

Cashdan, S. (2000). La bruja debe morir. De qué modo influyen los cuentos de hadas en los niños. Madrid, España: Debate.

Collodi, C. (Ilustraciones de Sánchez, J. M.). (1983). Pinocho. San José: Editorial Costa Rica.

Collodi, C. (Selección y compilación de ilustraciones de Edens, C.). (2003). Pinocho. Barcelona, España: Ediciones B, Grupo Z.

Collodi, C. (Ilustraciones de Innocenti, R.). (2005). Las aventuras de Pinocho. Sevilla, España: Kalandraka.

Consejo Superior de Educación (2008). Textos para I y II Ciclos de la Educación General Básica. San José, Costa Rica: Lehmann.

Disney, W. (Productor) \& Luske, H. (Director). (1940). Pinocho. [Cinta cinematográfica]. EE. UU.: Walt Disney Pictures.

Hazard, P. (1989). Los libros, los niños y los hombres. La Habana, Cuba: Gente Nueva.

Lionni, L. (Junio, 1985). Ante las imágenes. En Parapara, $N^{\circ} 11$, pp. 26-33. 
Lluch, G. (2004). Cómo analizamos relatos infantiles y juveniles. Bogotá, Colombia: Grupo Editorial Norma.

Molpeceres, M., Llinares, L. y Musitu, G. (2001). Internalización de los valores sociales y estrategias educativas familiares. En Ros, M. y Gouveia, V. (2001). Psicología social de los valores humanos. Madrid, España: Biblioteca Nueva.

Olbius Suari, N. (Noviembre, 2003). Pinocho de Innocenti: el encanto de la pulcritud. En Cuadernos de Literatura Infantil y Juvenil (CLIJ), Año 16, No 165, pp. 44-49.

Pascual, E. (Noviembre, 2003). La historia de un muñeco. En Cuadernos de Literatura Infantil y Juvenil (CLIJ), Año 16, No 165, pp. 21-28.

Sachs, J. (2006). El Fin de la Pobreza. México: Debate.

Schwartz, R. (2001). ¿Existen aspectos universales en la estructura y contenido de los valores? En Ros, M. y Gouveia, V. (2001). Psicología social de los valores humanos. Madrid, España: Biblioteca Nueva.

Soriano, M. (1995). La literatura para niños y jóvenes. Guía de exploración de sus grandes temas. Buenos Aires, Argentina: Ediciones Colihue. 